for: Abbvie, UCB, MSD, Novartis, Speakers bureau: BMS, AbbVie, Pfizer, MSD, Michael Nurmohamed Grant/research support from: AbbVie, BristolMyers Squibb, Celgene, Eli Lilly, Janssen, Menarini, MSD, Mundipharma, Pfizer, Roche, Sanofi and UCB, Consultant for: AbbVie, Bristol-Myers Squibb, Celgene, Eli Lilly, Janssen, Menarini, MSD, Mundipharma, Pfizer, Roche, Sanofi and UCB, Speakers bureau: AbbVie, Bristol-Myers Squibb, Celgene, Eli Lilly, Janssen, Menarini, MSD, Mundipharma, Pfizer, Roche, Sanofi and UCB

DOI: 10.1136/annrheumdis-2019-eular.5703

\section{THU0370 PERFORMANCE OF THE ANKYLOSING SPONDYLITIS DISEASE ACTIVITY SCORE (ASDAS) IN PATIENTS WITH PERIPHERAL AND AXIAL SPONDYLOARTHRITIS IN CLINICAL PRACTICE}

Esther Beckers ${ }^{1}$, Marin Been ${ }^{1}$, Casper Webers ${ }^{1}$, Annelies Boonen ${ }^{1}$, Peter Ten Klooster ${ }^{2}$, Harald Vonkeman ${ }^{2}$, Astrid van Tubergen ${ }^{1} .{ }^{1}$ MUMC, Rheumatology, Maastricht, Netherlands, ${ }^{2} \mathrm{MST}$, Rheumatology, Enschede, Netherlands

Background: The Ankylosing Spondylitis Disease Activity Score (ASDAS) is a widely used composite measure of disease activity in axial spondyloarthritis $(a x S p A)$. Such a tool is lacking for peripheral SpA (pSpA). However, the ASDAS also assesses peripheral joint symptoms. Previously, trial data have shown that the ASDAS has high sensitivity to change and high discriminatory ability between disease states in $\mathrm{PSpA}$ (1). We hypothesized that the ASDAS can be used to measure disease activity in all patients with $\mathrm{pSpA}$ in clinical practice.

Objectives: To investigate the construct validity of the ASDAS in pSpA in comparison with axSpA in clinical practice.

Methods: Data from a registry for SpA in the Netherlands (SpA-Net) were used. Construct validity of the ASDAS was assessed by testing hypotheses about Spearman correlations with other outcomes measures including individual components of disease activity, physical functioning and health-related quality of life (HRQoL). Construct validity was also assessed by stratifying patients according to ASDAS cut-offs to compare means of different health outcomes across ASDAS states by one-way ANOVA analyses. All analyses were repeated after stratification for the presence/absence of psoriasis in $\mathrm{pSpA}$. Results were compared to the performance of the ASDAS in axSpA.

Results: In total, 194 patients with pSpA and 222 patients with axSpA were included. Poor to high correlation was found between ASDAS and measures of disease activity $\left(\mathrm{r}_{\mathrm{s}} 0.20\right.$ to 0.78$)$, a moderate correlation was found between ASDAS and measures of physical functioning $\left(r_{s} 0.61\right.$ to 0.64 ) and a poor to moderate correlation was found between ASDAS and measures of $\mathrm{HRQoL}$ in PSpA $\left(\mathrm{r}_{\mathrm{s}}-0.27\right.$ to -0.66$)$ (table 1). With increasing ASDAS states, significantly worse scores were found on (other) measures of disease activity, physical functioning and HRQoL in $\mathrm{pSpA}$ (table 2). Stratification for the presence/absence of psoriasis showed similar results (data not shown). All results for $\mathrm{pSpA}$ were comparable to axSpA (see for example Table 1).

Abstract THU0370 - Table 1. Construct validity of ASDAS with health outcomes in pSpA and axSpA

\begin{tabular}{lcc}
\hline & pSpA $\mathbf{n = 1 9 4}$ & axSpA $\mathbf{n = 2 2 2}$ \\
\hline Disease activity & & \\
\hline BASDAl & 0.78 & 0.81 \\
Patient global & 0.77 & 0.75 \\
CRP & 0.41 & 0.51 \\
VAS pain & 0.73 & 0.67 \\
Physician global & 0.55 & 0.46 \\
TJC68 & 0.38 & 0.28 \\
SJC66 & 0.20 & 0.24 \\
Physical functioning & & \\
BASFI & 0.61 & 0.59 \\
HAQ-S & 0.62 & 0.58 \\
ASAS-HI & 0.64 & 0.46 \\
Quality of life & & \\
EQ5D & -0.56 & -0.40 \\
SF36 MCS & -0.27 & -0.26 \\
SF36 PCS & -0.66 & -0.54 \\
All correlations were statistically significant $(p<0.05)$ &
\end{tabular}

Criteria for correlations: $r_{\mathrm{s}}<0.29$ poor, $0.30 \leq r_{\mathrm{s}}<0.49$ low, $0.50 \leq r_{\mathrm{s}}<0.69$ moderate, 0.70 $\leq r_{\mathrm{s}}<0.89$ high and $r_{\mathrm{s}} \geq 0.90$ very high

Abstract THU0370 - Table 2. Health outcomes according to ASDAS states in pSpA

\begin{tabular}{lccccc}
\hline ASDAS cut-off & $<\mathbf{1 . 3}$ & $\mathbf{1 . 3}$ to $<2.1$ & $\mathbf{2 . 1}$ to $\leq \mathbf{3 . 5}$ & $>\mathbf{3 . 5}$ & p-value \\
Disease activity & $\mathbf{n}=\mathbf{4 0}$ & $\mathbf{n}=\mathbf{5 9}$ & $\mathbf{n}=\mathbf{8 1}$ & $\mathbf{n}=\mathbf{1 4}$ & \\
\hline BASDAI & $1.6(1.0)$ & $2.9(1.4)$ & $5.1(1.8)$ & $7.1(1.3)$ & $<0.01$
\end{tabular}

\begin{tabular}{lccccc} 
Patient global & $1.2(1.1)$ & $2.7(1.7)$ & $5.0(2.1)$ & $7.4(1.9)$ & $<0.01$ \\
CRP & $1.7(1.3)$ & $3.4(3.6)$ & $5.4(7.3)$ & $9.0(7.2)$ & $<0.01$ \\
VAS pain & $1.1(1.6)$ & $2.6(2.3)$ & $5.3(2.2)$ & $6.5(1.3)$ & $<0.01$ \\
Physician global & $0.9(0.9)$ & $1.2(0.1)$ & $2.4(1.8)$ & $4.4(1.6)$ & $<0.01$ \\
TJC68 & $0.2(0.4)$ & $1.2(3.8)$ & $2.1(4.0)$ & $2.6(2.5)$ & $<0.05$ \\
SJC66 & $0.1(0.4)$ & $0.4(1.0)$ & $0.5(1.2)$ & $0.6(0.9)$ & 0.29 \\
Physical functioning & & & & & \\
BASFI & $1.1(1.4)$ & $2.1(2.0)$ & $4.0(2.2)$ & $5.4(2.4)$ & $<0.01$ \\
HAQ-S & $0.3(0.3)$ & $0.7(0.6)$ & $1.0(0.6)$ & $1.5(0.8)$ & $<0.01$ \\
ASAS-HI & $2.8(2.7)$ & $4.6(3.1)$ & $7.0(3.2)$ & $9.4(1.8)$ & $<0.01$ \\
HRQoL & & & & & \\
EQ5D & $0.9(0.1)$ & $0.8(0.1)$ & $0.7(0.2)$ & $0.6(0.3)$ & $<0.01$ \\
SF36 MCS & $52.8(8.1)$ & $52.7(9.7)$ & $47.1(10.7)$ & $41.5(14.1)$ & $<0.01$ \\
SF36 PCS & $48.9(8.3)$ & $40.6(10.7)$ & $35.1(7.6)$ & $29.5(5.6)$ & $<0.01$ \\
Values are expressed as mean (SD) & & & & \\
\hline
\end{tabular}

Conclusion: The ASDAS demonstrated similar construct validity in all patients with $\mathrm{pSpA}$ and axSpA in clinical practice. Therefore, the ASDAS can also be used to measure disease activity in $\mathrm{pSpA}$ in daily practice.

\section{REFERENCE:}

[1] Turina MC, et al. A psychometric analysis of outcome measures in peripheral spondyloarthritis. ARD 2016;75:1302-7.

Disclosure of Interests: None declared

DOI: 10.1136/annrheumdis-2019-eular.1617

\section{THU0371 PREVALENCE OF WORK DISABILITY AND PREDICTORS OF WORK PRODUCTIVITY AMONG EMPLOYABLE PATIENTS WITH ANKYLOSING SPONDYLITIS AND PSORIATIC ARTHRITIS IN A CANADIAN REAL WORLD OBSERVATIONAL COHORT INTERIM RESULTS FROM THE COMPLETE STUDIES}

Louis Bessette $^{1}$, Valencia P. Remple ${ }^{2}$, Samuel Silverberg ${ }^{3}$, Viktoria Pavlova ${ }^{4}$, Majed Khraishi'. 'Laval University, Centre Hospitalier de l'Université Laval, Quebec, Canada: ${ }^{2}$ AbbVie Corporation, Montreal, Canada; ${ }^{3}$ Etobicoke General Hospital, Toronto, Canada; ${ }^{4}$ McMaster University, Hamilton, Canada; ${ }^{5}$ Memorial University of Newfoundland, St. John's, Canada

Background: Work disability is an important functional outcome among patients with chronic inflammatory diseases such as ankylosing spondylitis (AS) and psoriatic arthritis (PsA). Maintenance of patients in the work force and return to employment are important treatment outcomes with implications for both patients and the healthcare system.

Objectives: The aim of this analysis is to describe the prevalence of unemployment due to disability at baseline and to identify factors associated with work productivity loss in patients with AS and PsA followed in Canadian routine clinical care.

Methods: Patients eligible for the COMPLETE studies were anti-TNFo naïve adults, with active AS or PsA per the judgment of the treating physician, who required change in their treatment regimen. This interim analysis included patients that were treated with adalimumab or non-biologic DMARDs and, were either employed or on disability at baseline. Work productivity was measured by the Work Limitations Questionnaire (WLQ). Depression was defined as a Beck's Depression Inventory (BDI) score $\geq 20$ and/or treatment with an antidepressant/anxiolytic at baseline. Multivariate generalized linear models were used to identify determinants of\% WLQ productivity loss (WLQ-PL) scores at 6 and 12 months of treatment, along with the respective changes from baseline. Least Square Means (LSM) for the WLQ-PL improvement were reported from the multivariate model.

Results: A total of 486 AS patients and 292 PsA patients were included in the analysis. The mean (SD) disease duration was 5.2 (8.6) and 12.8 (12.1) years, mean (SD) age was 41.7 (11.6) and 48.3 (10.5) years, and male predominance was $58.4 \%$ and $54.5 \%$, in the AS and PsA groups, respectively. At baseline, $13.4 \%$ of AS patients and $17.8 \%$ of PsA patients were unemployed due to disability.

Among employed patients, the mean (SD) WLQ-PL score at baseline was $9.2 \%(5.7)$ in the AS patient group and $8.3 \%(6.0)$ in the PsA patient group. After 6 months of treatment significant improvement was observed in both patient populations $\left(\Delta_{\mathrm{AS}}[95 \% \mathrm{Cl}]\right.$ : $-2.7 \% \quad[-3.4,-2.0]$ $\Delta_{\text {PsA }}[95 \%$ Cl] : $-2.1 \%[-2.9,-1.3])$ which was maintained until 12 months. Among AS patients, after adjusting for baseline parameters including age, sex, tobacco use, HLA B27 status, treatment group, depression, and baseline scores for BASFI and WLQ-PL using multivariate analysis, presence of depression (LSM: $-0.2 \%$ vs. $-2.5 \% ; \mathrm{p}=0.016$ ) and female sex (LSM: $-0.7 \%$ vs. $-2.0 \% ; p=0.047$ ) were identified as significant negative 